\title{
Ocular Manifestations of Schimmelpenning-Feuerstein- Mims syndrome - A Rare Phakomatosis
}

\section{Sharah Rahman ${ }^{1 *}$, Sarwar Alam ${ }^{1}$, Chandana Sultana ${ }^{1}$, Mahmood Mujtaba $^{1}$, Abdus Salam ${ }^{1}$, ASM Moinuddin ${ }^{1}$ and Rashed Alam ${ }^{1}$}

${ }^{1}$ Department of Cornea and Anterior Segment, Ispahani Islamia Eye Institute and Hospital, Dhaka, Bangladesh

*Corresponding Author: Sharah Rahman, Department of Cornea and Anterior Segment, Ispahani Islamia Eye Institute and Hospital, Dhaka, Bangladesh
Received: March 08, 2021

Published: April 17, 2021

(C) All rights are reserved by Sharah Rahman., et al.

\section{Abstract}

Schimmelpenning-Feuerstein-Mims (SFM) syndrome is a rare phacomatosis characterized by sebaceous nevus of Jadasson associated with extracutaneous abnormalities affecting the brain, eyes and bones. Though Nevus sebaceous is the most common type of organoid epidermal nevus, but its association with Schimmelpenning-Feuerstein-Mims syndrome is rarely established. The purpose is to report the ocular manifestations of Schimmelpenning-Feuerstein-Mims syndrome of an 11-year-old boy. The patient had the classic triad of epibulbar choristomas, lid and retinal coloboma, and nevus sebaceus of Jadassohn. His vision in right eye was 1.00 and left eye was 0.30 in LogMAR chart. He had lid coloboma, multiple limbal and scleral choristoma, cloudy cornea, retinal and optic disc coloboma in right eye. Left eye had limbal dermoid but cornea was relatively clear with a normal fundus. A brownish black verrucous plaque on the right facial area was discovered spreading ipsilaterally to the cervical region, combined with cicatricial alopecia, microtia, periocular nodule and pigmentation. The retinal and optic disc coloboma was confirmedwith B scan ultrasonography of right eye.

Keywords: Nevus sebaceous of Jadassohn; Phacomatosis; Limbal dermoid; Coloboma; Epibulbar choristomas

\section{Abbreviation}

SFM: Schimmelpenning-Feuerstein-Mims

\section{Introduction}

Linear nevus sebaceus of Jadassohn, also known as organoid nevus syndrome or Schimmelpenning - Feuerstein-Mims syndrome (SFM) is a rare congenital phacomatosis initially defined by the dermatologist Josef Jadassohn in 1895 [1]. It is a congenital hamartomatous lesion characterized by cutaneous sebaceous nevus, seizures, and ocular abnormalities [2]. Numerous cutaneous, skeletal, neurologic, cardiovascular and ocular neoplasm and malformations have been termed as a part of SFM syndrome [3] Epi- bulbar choristomas is the most common ocular association [4-6]. The ocular, cutaneous and CNS manifestations are listed in table 1-3 respectively. The different collaboration of the nevus sebaceous of Jadassohn with these findings is quite comparable to the oculo-neuro- cutaneous syndromes, or phakomatosis and described as organoid nevus syndrome [5,7]. The sebaceous nevi strictly follow the 'lines of Blaschko' (Figure 3) which is a prototype of dermatological 'nevus lines' ofhead and neck named after Blaschko [3]. The ocular manifestations of Schimmelpenning-Feuerstein-Mims syndrome were rarely reported by the ophthalmologist. We report an 11 year old boy with organoid nevus syndrome giving emphasis on the ocular findings. 


\begin{tabular}{|l|c|}
\hline \multicolumn{1}{|c|}{ Ocular structure } & Features \\
\hline Globe & Microphthalmos \\
\hline Orbit & Proptosis \\
\hline Lid & Naevus, Coloboma, Hemangioma \\
\hline Conjunctiva/episclera & $\begin{array}{c}\text { Choristoma (most common), Dermoid } \\
\text { Epidermoid, Complex choristoma, } \\
\text { Vascular hemangioma }\end{array}$ \\
\hline Sclera & $\begin{array}{c}\text { Epi/intra-scleral cartilage, Epi/ } \\
\text { intra-scleral bone, } \\
\text { Posterior scleral choristoma }\end{array}$ \\
\hline Cornea & Choristoma, Cloudy cornea \\
\hline Anterior chamber & $\begin{array}{c}\text { Axenfeld anomaly, Posterior } \\
\text { embryotoxon }\end{array}$ \\
\hline Lens & Cataract \\
\hline Retina & Coloboma, Coats disease \\
\hline Choroid & Coloboma, Osteoma \\
\hline Optic nerve & Coloboma, Pit, Hypoplasia, Glioma \\
\hline
\end{tabular}

Table 1: Ocular manifestations of Schimmelpenning -Feuerstein-Mims syndrome.

\begin{tabular}{|c|}
\hline $\begin{array}{c}\text { Linear nevus usually respecting the midline, most commonly } \\
\text { found on the scalp, retro auricular area andneck [5] }\end{array}$ \\
\hline Alopecia \\
\hline Sebaceous lobules \\
\hline Malignant degeneration in $10 \%-20 \%$ of cases [2] \\
\hline Basal Cell Carcinoma [9] \\
\hline Verrucous plaque \\
\hline
\end{tabular}

Table 2: Cutaneous manifestations of Schimmelpenning -Feuerstein-Mims syndrome.

\begin{tabular}{|c|}
\hline Seizures \\
\hline Mental retardation \\
\hline Structural brain defects \\
\hline Various deficits \\
\hline Strabismus \\
\hline Nerve palsies \\
\hline Pupillary abnormalities \\
\hline
\end{tabular}

Table 3: CNS manifestations of Schimmelpenning -Feuerstein-Mims syndrome.

\section{Case Report}

An 11 year old boy came to the cornea clinic of Ispahani Islamia Eye Institute and hospital with the complaints of dimness of vision in both eyes, right more than left since childhood. On examination, we found that his best corrected visual acuity (BCVA) in right eye was 6/60, 20/200, 1.00 and in left eye was 6/12, 20/40, 0.30 in Snellen chart, 20/20 chart and LogMAR chart respectively. In right eye, the clinical features included eyelid coloboma (Figure 1), multiple limbal and scleral dermoid (Figure 2) known as epibulbar choristoma, cloudy cornea, early cataract (Nuclear sclerosis 1) retinal coloboma, and optic disc coloboma (Figure 6 and 7). In left eye, the clinical features were limbal dermoid, partial corneal opacity with a normal fundus. The intraocular pressure was $17 \mathrm{mmHg}$ and 14 $\mathrm{mmHg}$ in right and left eye respectively bynon-contact tonometry. The systemic features involved a brownish black verrucous plaque on the right fronto- parietal area spreading ipsilaterally to the cervical region described as Linear Nevus of Jadasson that respects the 'lines of Blaschko' (Figure 4). There was Right fronto-parietal cicatricial alopecia (Figure 4), microtia, combined with periocular nodule and pigmentation (Figure 5). We did the complete neurological examination of the boy. His IQ scoring was average (90 - 109) [8] and gave no history of Seizure. His birth history was insignificant with a normal vaginal delivery at home. None of his family member were affected by a similar disease. The diagnosis was mostly clinical and the optic disc and retinal coloboma was confirmed by $\mathrm{B}$ scan ultrasonography of right eye (Figure 6) which showed hyper echogenic posterior pole lesion suggestive of definitive coloboma and orbital shadowing suggestive of posterior scleral choristoma. Color fundus photography of right eye showed optic disc coloboma and retinal coloboma (Figure 7). We prescribed spectacle for the vision improvement and tear substitute as supportive treatment. No definitive treatment was given. We planned to observe the patient regularly for development of further ocular complications like cataract or secondary glaucoma and systemic complications like seizure or any malignant transformations of the skin lesions.

\section{Discussion}

The ocular manifestations of the SFM syndrome is one of the fundamental features of the disease [11]. Epibulbar choristoma is the commonest features reported till date of this disease which ranges from a single dermoid to a complex choristoma [12,13]. Clarissa Patias [14] has reported a case of twin sisters who presented with organoid naevus syndrome with epileptic seizure and arachnoid 


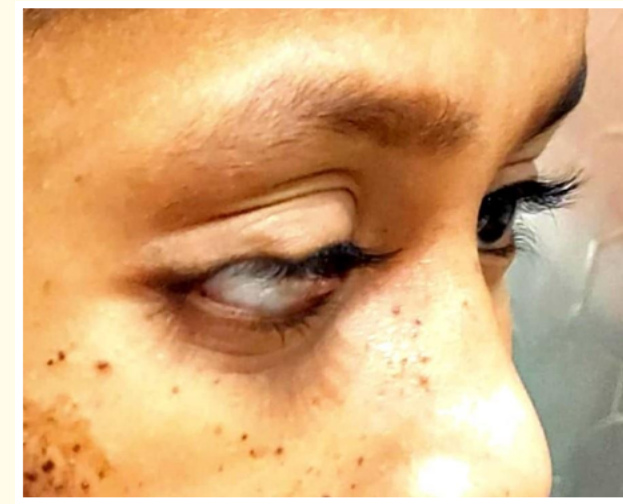

Figure 1: Lid coloboma.

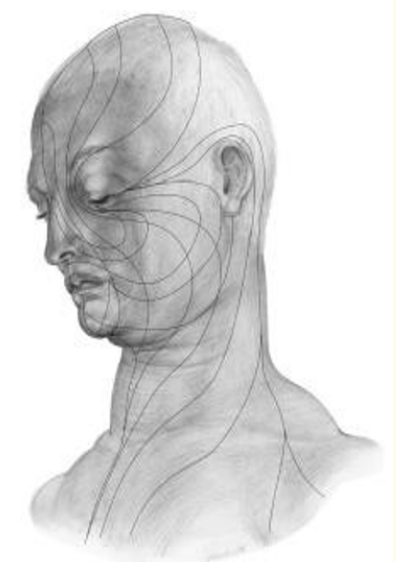

Figure 3: The 'lines of Blaschko' are a prototype of dermatological 'nevus line' of head and neck named after Blaschko respected in many congenital and acquired disorder [10] including SFM syndrome.

cyst. Various type offundus lesions have been observed by different authors that include hypopigmented yellowish-orange wedges of retina, retinal and optic disc coloboma, optic nerve hypoplasia $[5,15]$. Traboulsi., et al. [2] described four cases of nevus sebaceus of Jadassohn which were associated with posterior scleral choristoma and confirmed by histopathological examination. In our case, we report complex choristoma with posterior scleral involvement along with optic disc and retinal coloboma which was confirmed by B scan ultrasonography. We also found unilateral right sided brow-

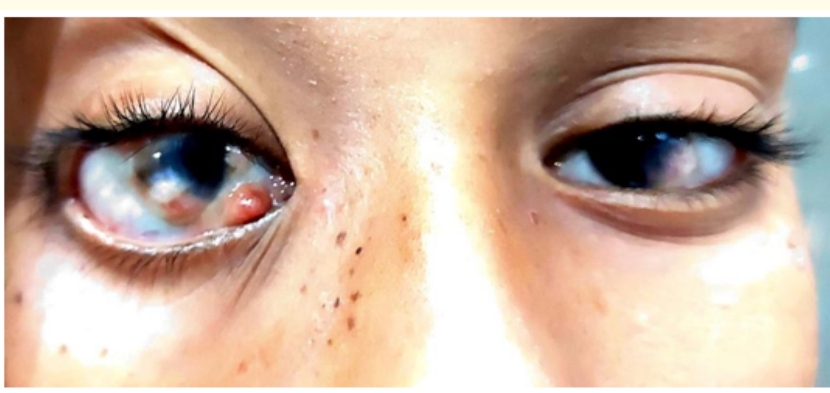

Figure 2: Multiple limbal and scleral dermoid with cloudy cornea.

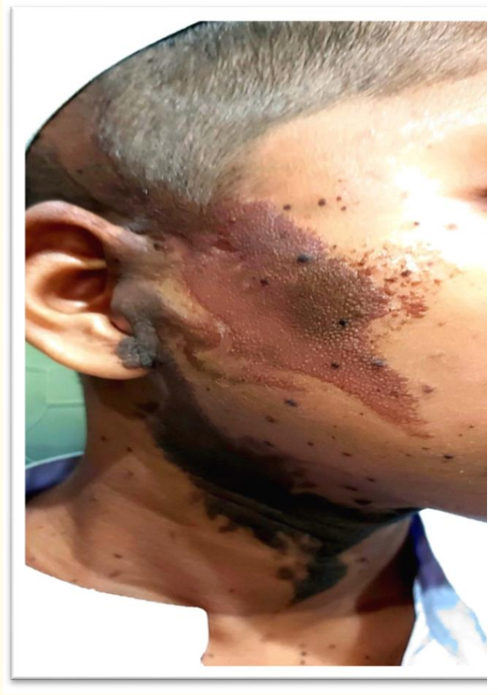

Figure 4: Linear Naevus of Jadasson along with Brownish plaque respecting 'lines of Blaschko', Right fronto-parietal cicatricial alopecia.

nish black nevus involving the temporal area spreading to cervical region. Right sided microtia, alopecia and hyperpigmentation were also described in our case. Different case reports from different country has reported similar neurocutaneous features [2,5,16,17]. In our study, the main culprit of vision loss is cloudy cornea along with optic nerve and retinal coloboma rather than epibulbar choristoma which is likewise established by Shields., et al [5]. 


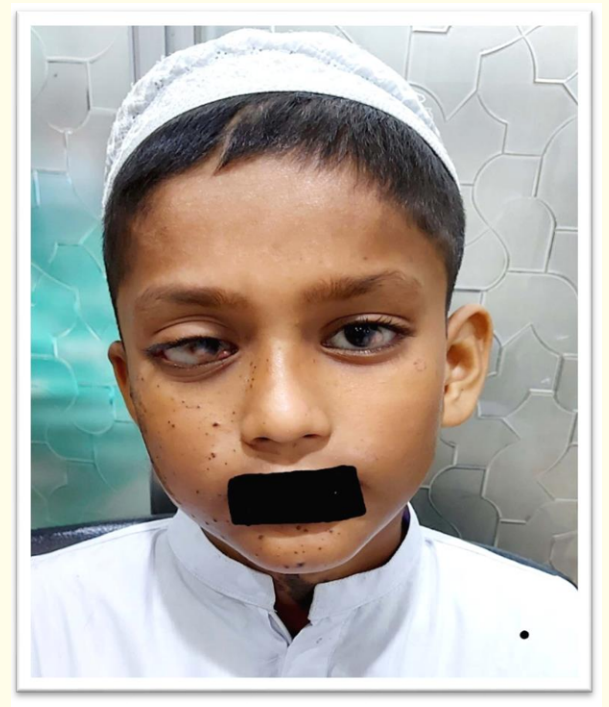

Figure 5: Right microtia, combined with periocular nodule and pigmentation.

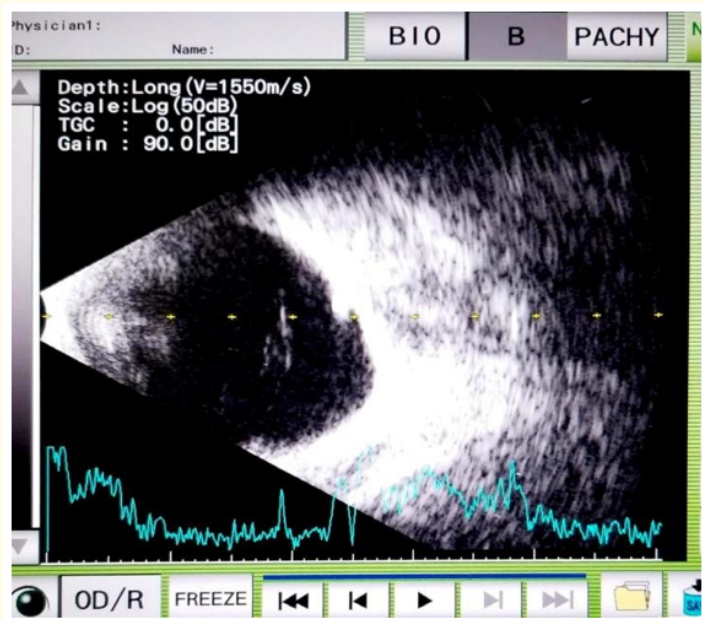

Figure 6: Hyperechogenic posterior pole lesion suggestive of optic disc coloboma with orbital shadowing suggestive of posterior scleral choristoma.

\section{Conclusion}

Patients with Schimmelpenning -Feuerstein-Mims syndrome should be examined for ocular malformations and observe closely

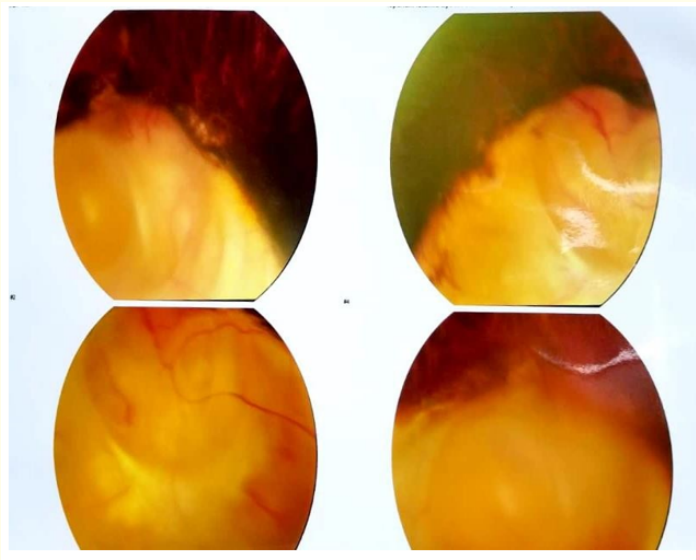

Figure 7: Optic disc coloboma and retinal coloboma.

for the development of malignant tumors. Though epilepsy is an important feature of the disease, but does not necessarily always present. No treatment is usually necessary but regular follow up is mandatory to manage the further ocular complications like cataract and glaucoma.

\section{Acknowledgements}

All of my mentors of the cornea department of Ispahani Islamia Eye Institute and Hospital for their continuous support and encouragement. The retina department of the esteemed institute for providing the investigation documents. Special gratitude to my mentor Professor Sarwar Alam sir for his constant guidance during the journey.

\section{Conflict of Interest}

No financial interest or any conflict of interest.

\section{Bibliography}

1. Weyers W. "Josef jadassohn--an appreciation on the occasion of his 150th birthday". The American Journal of Dermatopathology - LWW Journals 35.7 (2013): 742-751.

2. Elias I Traboulsi M., et al. "Posterior scleral choristoma in the organoid nevus syndrome (linear nevus sebaceus of Jadassohn)". American Academy of Ophthalmology 106.11 (1999): P2126-P2130. 
3. Warnke PH., et al. "The sebaceous nevus as part of the Schimmelpenning-Feuerstein-Mims Syndrome-an obvious phacomatosis first documented in 1927". Journal of Cutaneous Pathology 30.7 (2003): 470-472.

4. Hayasaka S., et al. "Epibulbar complex choristoma involving the bulbar conjunctiva and cornea". The Journal of Pediatric Ophthalmology and Strabismus 26.5 (1989): 251-253.

5. Shields JA., et al. "Ophthalmic features of the organoid nevus syndrome". Transactions of the American Ophthalmological Society 94 (1996): 65-87.

6. Garella M., et al. "Linear Nevus Sebaceus Syndrome with bilateral complex limbal choristomas and extraocular muscle involvement". Annals of Ophthalmology 36.1 (2004): 59-62.

7. Clancy RR., et al. "Neurologic Manifestations of the Organoid Nevus Syndrome". Archives of Neurology 42.3 (1985): 236-240.

8. Marwaha S. "Analysis of emotional quotient and intelligence quotient among 'High Achievers' and 'Low Performers' in school academics 26 (2015): 26-31.

9. Enei ML., et al. "Basal cell carcinoma appearing in a facial nevus sebaceous of Jadassohn: dermoscopic features". Anais Brasileiros de Dermatologia 87.4 (2012): 640-642.

10. Happle R and A Assim. "The lines of Blaschko on the head and neck". Journal of the American Academy of Dermatology 44.4 (2001): 612-615.

11. Lambert HM., et al. "Linear nevus sebaceous syndrome". Ophthalmology 94.3 (1987): 278-282.

12. Mansour AM., et al. "Bilateral Total Corneal and Conjunctival Choristomas Associated With Epidermal Nevus". Archives of Ophthalmology 104.2 (1986): 245-248.

13. Alfonso I., et al. "Linear nevus sebaceous syndrome. A review". Journal of Neuro-Ophthalmology 7.3 (1987): 170-177.

14. Lena CP., et al. "Do you know this syndrome? Schimmelpenning- Feuerstein-Mims syndrome". Anais Brasileiros de Dermatologia, 94 (2019): 227-229.

15. Wilkes SR., et al. "Ocular malformation in association with ipsilateral facial nevus of Jadassohn". American Journal of Ophthal- mology 92.3 (1981): 344-352.

16. Hagan WE. "Nevus sebaceus of Jadassohn: the head and neck manifestations". Laryngoscope 97.8-1 (1987): 909-914.

17. Duncan JL., et al. "Complex limbal choristomas in linear nevus sebaceous syndrome”. Ophthalmology 105.8 (1998): 14591465.

\section{Assets from publication with us}

- Prompt Acknowledgement after receiving the article

- Thorough Double blinded peer review

- Rapid Publication

- Issue of Publication Certificate

- High visibility of your Published work

Website: www.actascientific.com/

Submit Article: www.actascientific.com/submission.php

Email us: editor@actascientific.com

Contact us: +919182824667 